\title{
Update on diamondback moth (Plutella xylostella) insecticide resistance and the vegetable brassica insecticide management strategy
}

\author{
G.P. Walker ${ }^{1}$, S.I. Davis ${ }^{2}$, F.H. MacDonald ${ }^{1}$ and T.J.B. Herman ${ }^{3}$ \\ ${ }^{1}$ The New Zealand Institute for Plant E Food Research Limited, Private Bag 92169 \\ Auckland 1142, New Zealand \\ ${ }^{2}$ LeaderBrand Produce Ltd, PO Box 648, Gisborne 4040, New Zealand \\ ${ }^{3}$ Fruitfed Supplies, PO Box 322, Hastings 4156, New Zealand \\ Corresponding author: graham.walker@plantandfood.co.nz
}

\begin{abstract}
The susceptibility of field populations of diamondback moth (DBM), Plutella xylostella, to lambda-cyhalothrin, methamidophos, spinosad and indoxacarb collected from the four major brassica-growing regions has been assessed approximately every 2 years from 1997 to 2008. Recent results indicate that populations from all regions have increased their resistance to lambda-cyhalothrin, but there is little or no resistance to spinosad and indoxacarb and reduced resistance to methamidophos. This mitigation of resistance in DBM is attributed to, in particular, a decade-long regional adherence by the vegetable industry of rotating spinosad with indoxacarb in a two-windows-per-year rotation strategy. The original insecticide resistance management rotation strategy had to be updated to incorporate chlorantraniliprole registered as a foliar spray, and recently a mixture of chlorantraniliprole and thiamethoxam as a seedling drench. Seedling drenches have been removed from the twowindow strategy used for foliar sprays, with drenches now aligned with periods targeting the highest pest pressure, allowing mode of action (MoA)-free periods and rotation of different MoA insecticides to mitigate any resistance build-up in DBM.
\end{abstract}

Keywords diamondback moth, Plutella xylostella, insecticide resistance, insecticide resistance management rotation strategy.

\section{INTRODUCTION}

Over the last 25 years, researchers and the vegetable industry have developed, implemented and advanced an integrated pest management (IPM) programme for vegetable brassicas in New Zealand (Berry et al. 2000; Walker et al. 2009). The first implementation period was prompted by the build-up of resistance in diamondback moth (DBM), Plutella xylostella, to a standard pyrethroid, lambda-cyhalothrin. Resistance reached levels in three regions equivalent to those associated with control failures in North America (Cameron \& Walker 1998). The levels of resistance recorded for the standard organophosphate, methamidophos, were also likely to cause control failures (Cameron et al. 1997). The implementation phase of this IPM programme also included the publication of the first version of the IPM manual for vegetable brassicas, which included an insecticide resistance 
management rotation strategy (Berry et al. 2000). This strategy recommended that insecticides be applied only in response to pest populations exceeding the specific action thresholds for cabbage, cauliflower and broccoli, and that $\mathrm{Bt}$ (Bacillus thuringiensis) products be applied to early crop stages. Then, when applications of insecticides were required for control of lepidopteran pests, the strategy relied on the use of spinosad (Success ${ }^{\circledR}$ Naturalyte ${ }^{\circledR}$ ) in the first part of the season from September to late January (the early 'window'), at which time growers should stop using spinosad and change to using indoxacarb (Steward ${ }^{\circledR}$ ) from the beginning of February onwards (Berry et al. 2000; Walker et al. 2011). These dates divide the year equally into the same number of DBM generations, normally six generations, based on heat unit accumulations. Walker et al. (2004) reported that the vegetable industry accepted recommendations that long-term mitigation of insecticide resistance in DBM required regular monitoring of trends in resistance to the most commonly used insecticides in the major vegetable brassicagrowing regions. These surveys were supported by industry initiatives, including funding from agrichemical companies for surveys on the status of susceptibility of DBM populations to the newly registered products spinosad and indoxacarb. The trends in resistance were monitored by comparing susceptibilities with those of a standard susceptible laboratory colony that has been maintained at Mt Albert Research Centre, Auckland, without exposure to any insecticides since 1993 (Walker et al. 2011).

This IPM programme was updated in 2009 (Walker et al. 2009). However, the insecticide resistancemanagement rotation strategy for control of DBM now requires further modification. An informal DBM insecticide resistance management (IRM) working group was formed in 2009, consisting of the senior authors and New Zealandbased managers of the agrichemical companies that had insecticides registered for use in control of DBM in vegetable brassicas. This group liaised with regional grower representatives and the Brassica Crop Advisory Group of Vegetables New Zealand, to update the insecticide rotation strategy.
This group also liaised with representatives of the New Zealand Pesticide Resistance Management Committee and the international Insect Resistance Action Committee (IRAC) Diamide (Group 28) working group.

The aim of this paper is to report on the current status of insecticide resistance in DBM in New Zealand and to document the updated resistance management rotation strategy.

\section{CURRENT STATUS OF INSECTICIDE RESISTANCE IN DIAMONDBACK MOTH IN NEW ZEALAND}

Recently, Plant \& Food Research published the results of surveys of the levels of resistance in DBM collected from the key regions where vegetable brassicas are grown: Pukekohe, Gisborne, Horowhenua and mid Canterbury (Walker et al. 2011). Results indicated that populations from all regions have increased their resistance to lambda-cyhalothrin (Karate ${ }^{\circledR}$ Zeon), the standard pyrethroid tested, but there was little or no resistance to spinosad (Success ${ }^{\circledR}$ Naturalyte ${ }^{\circledR}$ ) and indoxacarb (Steward ${ }^{\circledR}$ ) and reduced resistance to the organophosphate, methamidophos. The highest level of resistance to lambda-cyhalothrin was 885 times in a population sourced from Pukekohe (compared with the susceptible reference colony), and DBM showed high levels of resistance to pyrethroids in all of the surveyed regions. The results also indicated that resistance was variable not only between regions but also within regions (Walker et al. 2011). DBM resistance to lambdacyhalothrin was significantly higher in South Auckland than elsewhere and resistance to this product has been increasing over time (Walker et al. 2004; Walker et al. 2011). This problem may well be due to continued use of this product for control of other insect pests in the warmer, northern regions of New Zealand, where the noctuid species Thysanoplusia orichalcea and Helicoverpa armigera are important caterpillar pests in summer and autumn crops (Walker et al. 2009). Lambda-cyhalothrin is also used in this region to control infestations of other insect pests in leafy vegetable crops (Young 2012). 


\section{THE INSECTICIDE RESISTANCE MANAGEMENT ROTATION STRATEGY FOR DIAMONDBACK MOTH}

Resistance in DBM to insecticide classes other than the pyrethroids appears to have been well managed over the last decade because of the country-wide adoption of an insecticide resistance management rotation strategy (Walker et al. 2004; Walker et al. 2011). This strategy depended on growers on a regional basis following IPM practices and using action thresholds to minimise spraying insecticides. When applications of insecticides were required, the two-window strategy was used, with products positioned for use either in an early- or a late-window period, with growers changing to an insecticide from a different group (with a different mode of action) at the end of each window period. It is believed this practice is the reason resistance in DBM has not developed to spinosad and indoxacarb in New Zealand. This strategy has had to be modified with the advent of new insecticide products, particularly to accommodate the use of pre-transplant drenches. The updated strategy is presented in Table 1. Table 2 presents a list of registered products and groups of insecticides used against brassica pests, their resistance grouping and activity profiles.

Table 1 Diamondback moth insecticide resistance management rotation strategy for vegetable brassicas (updated March 2012).

\begin{tabular}{|c|c|c|c|c|c|c|}
\hline \multicolumn{7}{|c|}{ INSECTICIDE USE WINDOWS: } \\
\hline Sep-Nov & Dec-Jan & Feb & Mar & Apr & May & Jun-Aug \\
\hline \multicolumn{7}{|c|}{ DIAMIDE/NEONICOTINOID INSECTICIDES } \\
\hline Transplant drench & \multicolumn{4}{|c|}{ 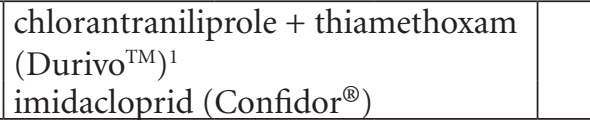 } & & \\
\hline Foliar spray & \multicolumn{4}{|c|}{ chlorantraniliprole $\left(\text { Coragen }{ }^{\circledR}\right)^{2}$} & & \\
\hline \multicolumn{7}{|c|}{ OTHER INSECTICIDE GROUPS ${ }^{3}$} \\
\hline \multicolumn{7}{|c|}{ Apply insecticides only in response to scouting thresholds } \\
\hline \multicolumn{7}{|c|}{ Bacillus thuringiensis $(\mathrm{Bt})^{4}$} \\
\hline \multicolumn{2}{|l|}{ indoxacarb (Steward $\left.{ }^{\circledR}\right)$} & \multicolumn{4}{|c|}{$\begin{array}{l}\text { spinosad (Success }{ }^{\circledR} \text { Naturalyte }^{\circledR} \text { ) } \\
\text { fipronil }\left(\text { Ascend }{ }^{\circledR} \text { ) }\right. \\
\text { synthetic pyrethroids }{ }^{5,7}\end{array}$} & \\
\hline \multicolumn{7}{|c|}{ organophosphates ${ }^{6,7}$} \\
\hline \multicolumn{2}{|c|}{ pymetrozine (Chess $\left.{ }^{\circledR}\right)$ (for aphids only) } & \multicolumn{5}{|c|}{ pirimicarb (for aphids only) $)^{7}$} \\
\hline
\end{tabular}

${ }^{1}$ Coragen ${ }^{\circledR}$ and Durivo ${ }^{\mathrm{TM}}$ have an active ingredient (chlorantraniliprole) in common. If Durivo ${ }^{\mathrm{TM}}$ is used (as a transplant drench), it should not be followed with Coragen ${ }^{\circledR}$ on that crop.

${ }^{2}$ Coragen ${ }^{\circledR}$ can be used (as a foliar spray) in the period 01-December to 30-April, but not on crops treated with Durivo $^{\mathrm{TM}}$ (as a transplant drench).

${ }^{3}$ From any one insecticide group, use a maximum of two consecutive applications (less than 15 days apart) in the life of a single crop.

${ }^{4}$ Apply Bt to small larvae on small plants.

${ }^{5}$ There is resistance to synthetic pyrethroids in some populations of diamondback moth (DBM). The use of this group should be avoided in areas where resistance is known to exist. Consult your local pest control advisor before use.

${ }^{6}$ Organophosphates are best used sparingly either against high infestations of early season seedling pests or as an end of crop 'clean-up' application.

${ }^{7}$ Green peach aphid, Myzus persicae, and onion thrips, Thrips tabaci, are known to be resistant to broadspectrum insecticides in New Zealand. Unnecessary application of these groups should be avoided as much as possible. 
Table 2 A list of registered products and groups of insecticides used against brassica pests, their Insect Resistance Action Committee (IRAC) resistance grouping and activity profiles against diamondback moth (DBM) and other key pests.

\begin{tabular}{|c|c|c|c|c|c|}
\hline \multirow[b]{2}{*}{ Product(s) } & \multirow[b]{2}{*}{ Active ingredient/group } & \multirow{2}{*}{$\begin{array}{l}\text { IRAC } \\
\text { resistance } \\
\text { group }\end{array}$} & \multicolumn{3}{|c|}{ Activity against key brassica pests ${ }^{1}$} \\
\hline & & & $\begin{array}{l}\text { DBM \& other } \\
\text { caterpillars }\end{array}$ & Aphids & Thrips \\
\hline Durivo $^{\mathrm{TM}}$ & $\begin{array}{l}\text { chlorantraniliprole+ } \\
\text { thiamethoxam }\end{array}$ & $28+4 \mathrm{~A}$ & Label & Label & Label \\
\hline Confidor $^{\circledR}$ & imidacloprid & $4 \mathrm{~A}$ & None & Label & Known \\
\hline Coragen ${ }^{\circledR}$ & chlorantraniliprole & 28 & Label & None & None \\
\hline Steward ${ }^{\circledR} 150$ SC & indoxacarb & $22 \mathrm{~A}$ & Label & None & None \\
\hline Chess ${ }^{\circledR}$ WG & pymetrozine & $9 B$ & None & Label & None \\
\hline Success ${ }^{\circledR}$ Naturalyte ${ }^{\circledR}$ & spinosad & 5 & Label & None & Known \\
\hline Ascend ${ }^{\circledR}$ & fipronil & $2 \mathrm{~B}$ & Label & None & Known \\
\hline Various & synthetic pyrethroids & $3 \mathrm{~A}$ & Label & Known & Known \\
\hline Various & organophosphates & $1 \mathrm{~B}$ & Label & Label & Known \\
\hline Various & pirimicarb & $1 \mathrm{~A}$ & None & Label & None \\
\hline
\end{tabular}

${ }^{1}$ Label $=$ NZ label claim; Known $=$ known activity; None $=$ no activity known.

\section{DISCUSSION}

IRM strategies overseas mainly recommend using a "window" approach to avoid exposure of consecutive insect pest generations to the same MoA (IRAC 2010). In Australia, a central component of the brassica IRM programme is a national "two-window" insecticide rotation strategy based on calendar windows similar to those used in New Zealand. Baker (2011) reports that the new Group 28 (diamides) foliar spray products were placed in the first window in 2009. Baker (2011) also notes that a future challenge looms with the anticipated registration of more Group 28 products and how to effectively incorporate new chemistries, particularly seedling drenches, into IRM strategies.

The new strategy in New Zealand has been designed to ensure that diamides are not used all year round, in order to preserve the effectiveness of these products for as long as possible. The window for use of Durivo ${ }^{\mathrm{TM}}$ drench has been moved to cover the main part of the year where DBM is an issue, i.e. drenching transplants from 1 December to 31 March (approximate harvest period 1 February to 30 June). This revised window has been designed so that there is an adequate window for at least the season's first generation of DBM to be completed in a diamide-free period. In the absence of Durivo ${ }^{\mathrm{TM}}$-drenched plants, the foliar spraying of chlorantraniliprole (Coragen ${ }^{\circledR}$ ) may be used within the same window period as for Durivo $^{\mathrm{TM}}$. However, Coragen ${ }^{\circledR}$ should never be applied to plants drenched with Durivo ${ }^{\mathrm{TM}}$.

Compared with the former strategy, the two 'soft' DBM insecticides, indoxacarb (Steward ${ }^{\circledR}$ ) and spinosad (Success ${ }^{\circledR}$ Naturalyte ${ }^{\circledR}$ ), have been transposed between the early and late windows. This means that spinosad will be used in the late season when its activity against thrips (as well as caterpillars) would be more useful. It is recommended that growers adopt this practice in other IPM programmes that use these two insecticides.

The new strategy has been designed assuming that the industry will retain the ability to use organophosphates as a "break group" for resistance management when required. Low use of organophosphates over recent years has resulted in a decline in organophosphate resistance in New Zealand populations of DBM (Walker et al. 2011), illustrating the importance of having multiple groups of insecticides available for effective resistance management. The current 
main uses of organophosphates are in transplant nurseries (as a replacement for groups that will be subsequently used in the field) and as late-season short withholding period clean-up applications. Other uses are against occasional establishment pests, such as wheat bug, thrips, greasy cutworm, leaf miners and springtails. It is recommended that organophosphates should be used only when there is a real need, with a maximum of two consecutive applications on a single crop. This should restrict organophosphates to a single pest generation in any location. If they are used in this way, it is considered that there is no need for a particular window for organophosphates. This will allow their use for crop clean-up, rotation breaks, or their availability to address issues such as leaf miners in leafy brassicas that can occur at any time and where organophosphates are an effective insecticide group.

Growers should monitor plants to ensure insecticides are applied only when necessary. The IPM programme developed by Plant \& Food Research includes a cost-effective crop scouting system and action thresholds for cabbage, cauliflower and broccoli crops (Walker et al. 2009). If the action thresholds for caterpillar pests are exceeded, growers should rotate insecticide groups in accordance with the national rotation strategy outlined above.

Growers throughout the country need to conform to this rotation strategy so that DBM populations do not develop resistance to any particular insecticide group. By rotating between different MoA groups of insecticides, any localised population that is developing resistance to a particular MoA will be reduced by the application of another group (MoA) of insecticide. The long-term sustainability of the updated IPM programme for vegetable brassicas relies on all brassica growers minimising insecticide use and using this updated insecticide rotation strategy.

\section{ACKNOWLEDGEMENTS}

The authors wish to acknowledge the contributions to the updated strategy by George Follas (Syngenta Crop Protection Ltd) and representatives of $\mathrm{Du}$ Pont Crop Protection, and Bruce Chapman (Insect Science Solutions). We also acknowledge the earlier work on development of IPM and IRM (insecticide resistance management) strategies for vegetable brassicas by Dr Peter Cameron and his research team. The resistance surveys were partly funded by MAF Sustainable Farming Fund project nos. 04/055, 07/017, 08/050, Du Pont (NZ) Ltd, and Dow Agrosciences (NZ) Ltd. Other work was partly funded by MAF Sustainable Farming Fund project grant no. 08/050, the Fresh Vegetable Product Group of Horticulture NZ and Plant \& Food Research.

\section{REFERENCES}

Baker GJ 2011. Crucifer vegetable insecticide resistance managment strategies and issues in Australia. In: Srinivasan R, Shelton AM, Collins HL ed. Proceedings of the Sixth International Workshop on Management of the Diamondback Moth and Other Crucifer Insect Pests, 21-25 March 2011, Kasetsart University, Nakhon Pathom, Thailand. Publication No. 11, AVRDC - The World Vegetable Center, Taiwan. Pp. 241-247.

Berry NA, Cameron PJ, Walker GP 2000. Integrated Pest Management for Brassicas, v.11. Crop \& Food Research, Christchurch, New Zealand. 71 p.

Cameron PJ, Walker GP 1998. Warning: diamondback moth resistant to pesticides. Commercial Grower 53: 12-13.

Cameron PJ, Shelton AM, Walker GP, Tang JD 1997. Comparative insecticide resistance of New Zealand and North American populations of diamondback moth, Plutella xylostella (Lepidoptera: Plutellidae). New Zealand Journal of Crop and Horticultural Science 25: 117-122.

IRAC Group 28 (Diamide) Working Group 2010. Insecticide Resistance Management Global Guidelines for IRAC Group 28 (Diamide) Insecticides. http://www.irac-online.org/ wp-content/uploads/2009/09/Global_IRM_ Guidelines_Group-28_v2.1.pdf (accessed 11 June 2012). 
Walker GP, Cameron PJ, Berry NA 2004. Implementing of an IPM programme for vegetable brassicas in New Zealand. In: Endersby NM, Ridland PM ed. The management of diamondback moth and other crucifer pests. Proceedings of the Fourth International Workshop, Melbourne, Australia, 26-29 November 2001. Pp. 365-370. Walker GP, MacDonald FH, Wallace AR 2011. Recent developments in management of diamondback moth in New Zealand. In: Srinivasan R, Shelton AM, Collins HL ed. Proceedings of the Sixth International
Workshop on Management of the Diamondback Moth and Other Crucifer Insect Pests, 21-25 March 2011, Kasetsart University, Nakhon Pathom, Thailand. Publication No. 11. AVRDC - The World Vegetable Center, Taiwan. Pp. 234-240.

Walker GP, Wright PJ, Cameron P, Berry NA 2009. Information guide for integrated pest management in vegetable brassicas. Fresh Vegetable Product Group of Horticulture New Zealand. ISBN 978-0-473-14901-7. 167 p.

Young S 2012. New Zealand Novachem Agrichemical Manual. AgriMedia Ltd. 723 p. 